\title{
Limits of grid extension in the Lao PDR: A financial perspective
}

\author{
Julius Susanto \\ Engineers Without Borders Australia, Melbourne \\ susanto@graduate.uwa.edu.au
}

\begin{abstract}
This paper articulates a financial model for estimating the limits of grid extension in the Lao PDR versus three decentralised renewable energy (DRE) options: micro-hydropower, pico-hydropower and solar photovoltaic. The model is based on a like-for-like comparison of the different DRE options against grid extension, such that each option supplies the same amount of electricity (in $\mathrm{kWh}$ ) over the project timeframe. The amount of electricity supplied is estimated based on the forecast electricity demand of a typical rural Lao household. Therefore, if a household consumes $7 \mathrm{kWh}$ per day, then the micro-hydro, pico-hydro, solar PV and grid extension systems are all sized in the model to supply $7 \mathrm{kWh}$ per day. This is in contrast to more conventional approaches, where grid extension is compared to DRE systems of typically lower capacities (e.g. grid extension compared against $50 \mathrm{~W}$ solar home systems). The limits of grid extension are expressed in terms of a breakeven distance, which is the maximum distance from a village at which grid extension is the more cost-effective option. Beyond this breakeven distance, DRE technologies can be installed at a lower cost, while providing the same amount of electricity to the end-use
\end{abstract}

KEYWORDS: Rural electrification, grid extension, distributed renewable energy, Lao PDR.

\section{INTRODUCTION}

The Lao PDR is a small landlocked country in Southeast Asia that is considered by the United Nations to be among the least developed countries. As part of a bid to graduate to developing country status, the Lao government has set an ambitious target to provide $90 \%$ of households with electricity by 2020 . Starting from a low base of around 15\% in 1995, the electrification rate has improved considerably, rising to a rate of 73\% in 2010 (EdL, 2011).

Throughout this period, the majority of new electricity connections were made via extension of the existing grid. This was reasonably cost-effective for connecting denser population centres, but this may not continue to be the most efficient option given that a large proportion of the remaining unelectrified households are located in the remote, less dense parts of the country. Depending on the remoteness of an unelectrified village, the costs of grid extension may be prohibitive and off-grid distributed renewable energy (DRE) sources may be a more economical option.

This paper presents a financial framework for analysing grid and off-grid electricity options for unelectrified villages in the Lao PDR, with the aim of investigating the limits to grid extension. A financial model is constructed, firstly taking into account electricity demand and then the costs of grid extension and three DRE technologies - micro-hydro, pico-hydro and solar photovoltaic systems. The limits of grid extension are then derived by calculating the "breakeven distance", defined here as the maximum distance from an unelectrified village at which grid extension is the more cost-effective option. The results of the analysis for the three DRE technologies are then presented, followed by a discussion of the model limitations and then finally some concluding remarks.

\section{BASELINE ELECTRICITY DEMAND}

The major difficulty with comparing grid and offgrid electricity options is the fact that a grid supply has the potential capacity to deliver a significantly higher power output to end-users (notwithstanding the technical issues associated with voltage support at the end of long lines). Therefore, in order for the comparisons to be valid, the same electricity demand data will be used for the analysis of both grid and off-grid options. 
The electricity demand is based on estimates of average household electricity demand in the Lao PDR. The total electricity demand for a village is then calculated by multiplying the household estimate by the number of households in the village. Three baseline electricity demand scenarios will be analysed - low, medium and high scenarios - to cover a range of possibilities in electricity demand.

\subsection{Household electricity demand estimates}

For this study, three baseline electricity demand scenarios are constructed based on the estimated average household demand for grid electricity in 2008 as per the Renewable Energy Master Plan (REMP) Vol 1 Part A Section 9.3.2 (Nippon Koei, 2010), and an additional estimate for very remote villages.

Note that the electricity demands shown in table 1 include an allowance of $30 \%$ for non-household demand.

Table 1: Average household electricity demand estimates for the north, south and remote regions of the Lao PDR.

\begin{tabular}{|c|c|c|}
\hline Scenario & $\begin{array}{c}\text { Demand (kWh/ } \\
\text { month/hh) }\end{array}$ & Remarks \\
\hline North & 39 & $\begin{array}{c}\text { Average of rural } \\
\text { northern provinces }\end{array}$ \\
\hline South & 78 & $\begin{array}{c}\text { Average of rural } \\
\text { southern provinces }\end{array}$ \\
\hline Remote & 13 & $\begin{array}{c}\text { Estimate for remote } \\
\text { villages }\end{array}$ \\
\hline
\end{tabular}

\subsection{Growth rates in electricity demand}

Household electricity demand has risen steadily in the Lao PDR over the last 20 years and it is expected that demand will continue to grow into the future. The financial model will make allowances for the growth rates in electricity demand as shown in table 2.

The sizing of equipment will be based on the prospective demand at the end of the project lifetime (e.g. 2030 for the 20 year timeframe).

Table 2: Demand growth rates.

\begin{tabular}{|c|c|l|}
\hline Time Period & Growth Rate & \multicolumn{1}{|c|}{ Remarks } \\
\hline Present -2020 & $5 \%$ & $\begin{array}{l}\text { Based on EdL } \\
\text { estimates in the } \\
\text { PDP (EdL, 2010) }\end{array}$ \\
\hline 2020 onward & $4 \%$ & $\begin{array}{l}\text { Based on REMP } \\
\text { Vol 1 Part A } \\
\text { Table 9.3.1 }\end{array}$ \\
\hline
\end{tabular}

\subsection{Load Profiles}

The literature on the load profiles of rural villages (Fall et al, 2007; Cross \& Gaunt, 2003; Ketjoy, 2005), particularly in sub-tropical Asian regions, suggest an average daily load profile with two major peaks - the first in the morning between 5 and 9 am and the second in the evening between 6 and $9 \mathrm{pm}$. The approximate daily load profile model (figure 1) is used in this study (note that the load profile is expressed in per unit quantities where $1.0 \mathrm{pu}$ is the peak load).

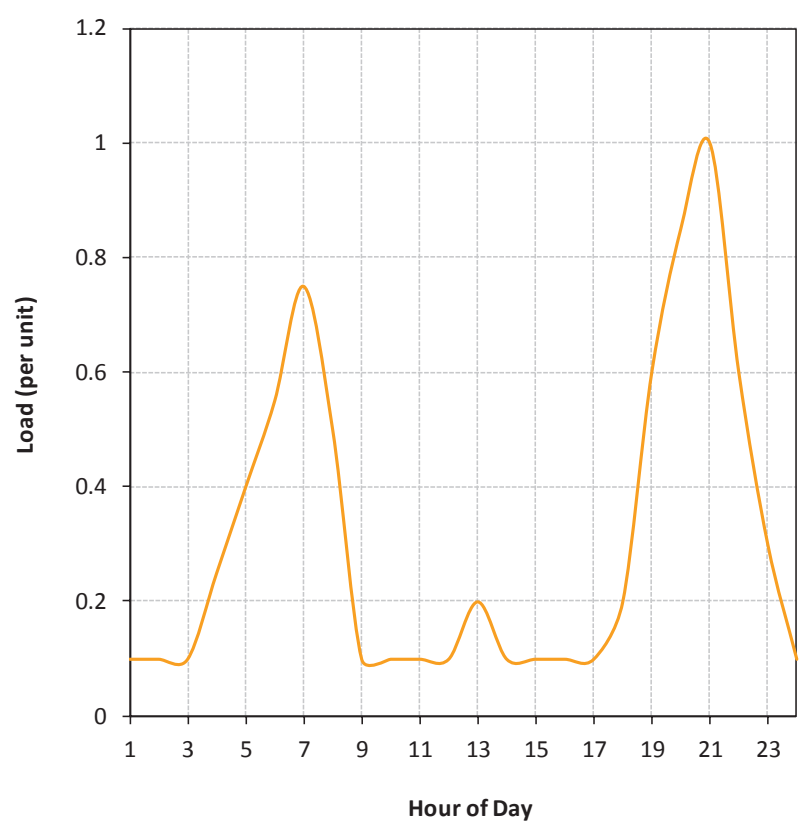

Figure 1: Approximate daily load profile model.

The approximate load profile above is intended to estimate the peak loading (in $\mathrm{kW}$ ) for a typical household, which will be used later for the sizing of micro- and pico- hydro systems.

To calculate the peak loading (in $\mathrm{kW}$ ) given a daily electricity demand (in $\mathrm{kWh} /$ day), the daily demand is fitted to the approximate load profile, such that the area under the curve is equal to the daily demand. The peak loading is the load of the fitted curve at approximately $9 \mathrm{pm}$.

\section{COSTS OF GRID EXTENSION}

The Levelised Cost of Electricity (LCOE) for grid extension is estimated by the following formula (LIRE, 2011):

$$
L C O E=L R M C+\frac{C A P E X+O \& M}{E}
$$

Where LCOE is the levelised cost of electricity (USD/kWh)

$L R M C$ is the long run marginal cost of electricity (USD/kWh) 
CAPEX is the capital cost for the grid extension, which includes the costs for MV transmission lines, distribution transformers and the LV distribution system (USD)

OEM is the operations and maintenance cost over the lifetime of the project, expressed as a net present value (USD)

$E$ is the useful energy output of the grid extension over the lifetime of the project (kWh), based on the baseline electricity demand estimates developed earlier.

\subsection{Long run marginal cost}

The long run marginal cost (LRMC) of electricity is the incremental cost of generating an additional $1 \mathrm{kWh}$. The LRMC is typically composed of two constituent parts -1 ) the marginal cost of additional generation capacity, and 2) the marginal cost of fuel / energy. Note that the LRMC reflects the cost borne by the producer to generate an additional $1 \mathrm{kWh}$, not the cost imposed on the end-user.

Table 3: Weighted average cost of past projects.

\begin{tabular}{|l|c|c|c|}
\hline Facility Name & $\begin{array}{c}\text { Capacity } \\
\text { (MW) }\end{array}$ & $\begin{array}{c}\text { Capital Cost } \\
\text { (millions } \\
\text { USD) }\end{array}$ & $\begin{array}{c}\text { Cost per } \\
\text { kW } \\
\text { (USD) }\end{array}$ \\
\hline Se Xet I & 45 & 42 & 933 \\
\hline Nam Ko & 1.5 & 9.8 & 6,533 \\
\hline Nam Leuk & 60 & 112.6 & 1,877 \\
\hline Nam Mang III & 40 & 63 & 1,575 \\
\hline \multicolumn{3}{|c|}{ WEIGHTED AVERAGE } & 1,552 \\
\hline
\end{tabular}

In this study, the LRMC is based on the cost of additional generation capacity through large hydropower (by far the most common source of electricity in the Lao PDR), which has a negligible marginal cost of fuel. Because a significant number of large hydropower projects are intended for export, only the facilities that are for domestic use are considered in this study.

As a proxy for the capital cost per $\mathrm{kW}$ for new hydropower capacity in the Lao PDR, the weighted average cost of past projects (intended for domestic supply) is used. Ideally, the LRMC would be based only on the capital costs of the newest projects, but doing so would result in too few data points.

The estimate of the LRMC is calculated as shown in table 4 below.

The annual O\&M costs are estimated based on values suggested by Goldsmith (1993) and the utilisation factor and T\&D losses are based on the EdL 2010 statistical yearbook (EdL, 2011).

It should be noted that for any sensitivity analysis, the maximum LRMC shall be capped at around US\$ $0.0496 / \mathrm{kW}$, which is the average price of electricity imports from neighbouring countries (EdL, 2011). The cost of producing electricity domestically cannot be higher than the import price, otherwise it would be more cost-effective to import electricity rather than generate it domestically at higher cost.

\subsection{Grid extension capitalcost}

In this paper, the capital costs of grid extension to an unelectrified village are based on a $12.7 \mathrm{kV}$ Single Wire Earth Return (SWER) line, one of the most common and cheapest types of grid extension to remote, low density areas. The costs are based on the figures in the REMP Study Table 9.2.1 (Nippon Koei, 2010) and summarised as shown in table 5.

Table 4: $\quad$ Estimate of long run marginal cost (LRMC) of electricity.

\begin{tabular}{|c|c|c|}
\hline \multicolumn{3}{|l|}{ Assumptions } \\
\hline Capital Cost & $\$ 1,552$ & $\mathrm{USD} / \mathrm{kW}$ \\
\hline Lifetime & 20 & Years \\
\hline Annual Operations and Maintenance (O\&M) Costs & $1.5 \%$ & of capital cost \\
\hline Utilisation Factor & 0.7 & $\mathrm{Pu}$ \\
\hline Transmission and Distribution (T\&D) Losses & $15 \%$ & \\
\hline \multicolumn{3}{|l|}{ Calculation } \\
\hline Annual Production & 6,132 & $\mathrm{kWh}$ per $\mathrm{kW}$ \\
\hline Annual O\&M Costs & $\$ 113.70$ & $\mathrm{USD} / \mathrm{kW}$ \\
\hline NPV of O\&M Costs (over power plant lifetime) & $\$ 1,116.32$ & $\mathrm{USD} / \mathrm{kW}$ \\
\hline NPV of Total Cost & $\$ 1,874.32$ & $\mathrm{USD} / \mathrm{kW}$ \\
\hline Estimated LRMC (without losses) & $\$ 0.01452$ & $\mathrm{USD} / \mathrm{kWh}$ \\
\hline Estimated LRMC (with losses) & $\$ 0.01670$ & $\mathrm{USD} / \mathrm{kWh}$ \\
\hline
\end{tabular}


Table 5: Summary of single wire earth return (SWER) costs.

\begin{tabular}{|c|c|c|}
\hline Component & $\begin{array}{c}\text { Cost } \\
\text { (USD) }\end{array}$ & Unit \\
\hline $12.7 \mathrm{kV}$ SWER & 18,544 & Per km \\
\hline $\begin{array}{l}12.7 / 0.4 \mathrm{kV} \text { single phase } \\
\text { distribution transformer }\end{array}$ & 113 & Per household \\
\hline $0.4 \mathrm{kV}$ distribution costs & 369 & Per household \\
\hline
\end{tabular}

The overall capital costs for grid extension can be expressed as a linear equation depending on the length of the grid extension $(L)$ and the number of households $(H)$ :

$$
C A P E X=18,544 \times L+482 \times H
$$

\subsection{Operations and maintenance costs}

The annual operations and maintenance (O\&M) costs are estimated to be $2 \%$ of the capital costs, as suggested by the REMP study (Nippon Koei, 2010). Over the lifetime of the project, the NPV of the O\&M costs is calculated as follows:

$$
O \& M_{N P V}=\frac{0.02 \times C A P E X}{r}\left[1-(1+r)^{-n}\right]
$$

\subsection{Total cost of grid extension}

Putting the CAPEX and O\&M costs together, the total cost of the grid extension (CAPEX + O\&M) can be expressed as a linear equation of the form:

$$
\text { Cost }_{\text {grid }}=a_{1} L+a_{2} H
$$

Where $L$ is the distance of the grid extension $(\mathrm{km})$ $H$ is the number of households in the village

$a_{1}$ is the coefficient of the grid extension corresponding to the distance (= US\$ $22,185 / \mathrm{km})$

$a_{2}$ is the coefficient of the grid extension corresponding to number of households (= US\$577/hh).

\section{COSTS OF MICRO-HYDROPOWER}

The Levelised Cost of Electricity (LCOE) for microhydro is estimated by the following formula:

$$
L C O E=\frac{C A P E X+O \& M+R}{E}
$$

Where $L C O E$ is the levelised cost of electricity (USD/kWh)

CAPEX is the capital cost (installed) of the micro-hydro facility (USD)

$O \mathcal{E} M$ is the operations and maintenance cost over the lifetime of the project, expressed as an NPV (USD)

$R$ is the replacement cost, expressed as an NPV (USD)

$E$ is the useful energy output of the grid extension over the lifetime of the project (kWh), based on the baseline electricity demand estimates developed earlier.

\subsection{Micro-hydro system sizing}

The sizing of a village micro-hydro system is based on the peak load demand of the village, and is computed as follows:

1. Calculate peak household load demand

The household electricity demand at the end of life (in $\mathrm{kWh}$ ) is used in conjunction with the typical household load profile in order to estimate the peak household load demand (in kW).

2. Calculate peak load demand of village

The peak load demand of the village can be estimated by multiplying the peak household load demand with the number of households in the village. In addition, a design allowance (typically $25 \%$ ) is added to obtain the final microhydro system size (in $\mathrm{kW}$ ). The design allowance captures inaccuracies in estimating the loads and a higher allowance can be used for more conservative estimates.

For example, suppose there is a village with 65 households and each household consumes $39 \mathrm{kWh}$ per month. The daily household consumption is

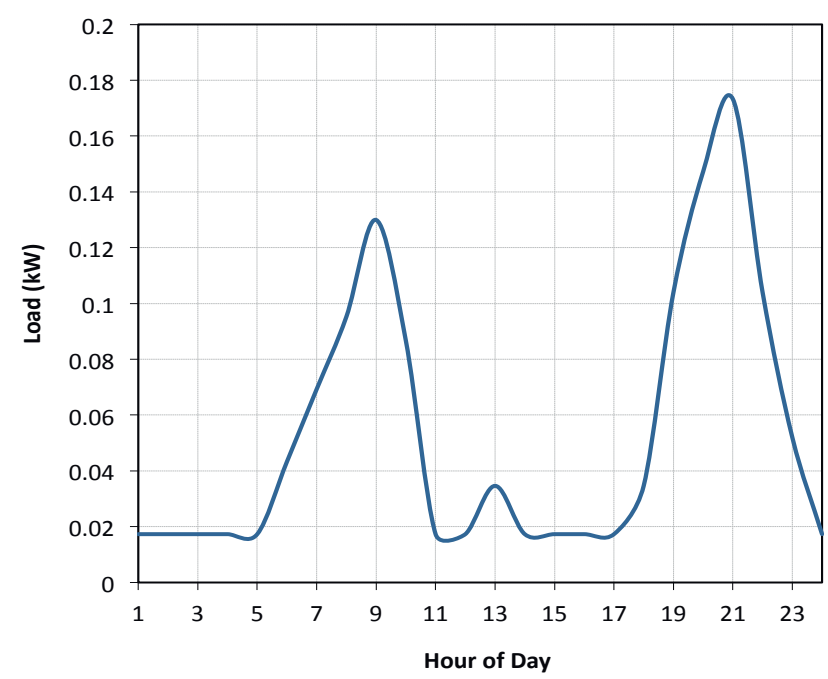

Figure 2: Daily household electricity consumption load profile. 
$1.282 \mathrm{kWh}$. Fitting this daily consumption onto the typical load profile, we get the load profile for each household as shown in figure 2 .

From the load profile, we can see that the peak household load demand is $0.173 \mathrm{~kW}$ at $9 \mathrm{pm}$. Multiplying by the total number of households, we get a peak village load demand of $65 \times 0.173=$ $11.245 \mathrm{~kW}$.

Applying the design allowance of $25 \%$, we get a final design size of $11.245 \times 125 \%=14.06 \mathrm{~kW}$. This is the size of the system that will be used in the subsequent cost calculations.

\subsection{Micro-hydro capital costs}

The capital costs of micro-hydro facilities are site specific and can be highly variable. However, a number of sources in the literature (Greacen, 2004; World Bank, 2006; IEA, 2005; Dhungel, 2009; Vaidya, 2002) estimate that the capital costs typically fall in the range of US $\$ 1,500$ to US $\$ 4,500$ per installed $\mathrm{kW}$ (adjusted to 2011 US Dollars), with a mean cost of US $\$ 2,500 / \mathrm{kW}$.

For this study, capital cost estimates are applied as shown in table 6.

The capital cost estimates above are total installed costs which include the micro-hydro system itself, civil works, transmission lines, transformers, low voltage distribution grid in the village and household connections and wiring.

Table 6: Micro-hydro capital cost estimates.

\begin{tabular}{|c|c|}
\hline Estimate Type & $\begin{array}{c}\text { Capital Cost } \\
\text { (USD/kW) }\end{array}$ \\
\hline Probable & 2,500 \\
\hline Low & 1,500 \\
\hline High & 4,500 \\
\hline
\end{tabular}

The capital cost estimates above are total installed costs which include the micro-hydro system itself, civil works, transmission lines, transformers, low voltage distribution grid in the village and household connections and wiring.

\subsection{Micro-hydro operations and maintenance costs}

From the literature (Greacen, 2004; World Bank, 2006; IEA, 2005; Dhungel, 2009; Vaidya, 2002), annual operations and maintenance costs are estimated to be in the range of 10 to $15 \%$ of the CAPEX. For the base financial model, $15 \%$ is used. Over the lifetime of the project, the NPV of the O\&M costs is calculated as follows:

$$
O \& M_{N P V}=\frac{0.15 \times C A P E X}{r}\left[1-(1+r)^{-n}\right]
$$

\subsection{Micro-hydro replacement costs}

It is assumed that over the 20 year lifetime of the project, no major equipment replacements are required and that the O\&M costs cover the costs of any replacement parts required.

\subsection{Total cost of micro-hydro}

Putting the CAPEX and O\&M costs together, the total cost of micro-hydro (CAPEX + O\&M) can be expressed as a linear equation of the form:

$$
\text { Cost }_{\text {micro }}=b_{1} H
$$

where $H$ is the number of households in the village $b_{1}$ is the cost coefficient of the micro-hydro system (USD).

\section{COSTS OF PICO-HYDROPOWER}

The Levelised Cost of Electricity (LCOE) for picohydro is estimated by the following formula:

$$
L C O E=\frac{C A P E X+O \& M+R}{E}
$$

where LCOE is the levelised cost of electricity (USD/kWh)

CAPEX is the capital cost (installed) of the pico-hydro system (USD)

$O \mathcal{E M}$ is the operations and maintenance cost over the lifetime of the project, expressed as an NPV (USD)

$R$ is the replacement cost, expressed as an NPV (USD)

$E$ is the useful energy output of the grid extension over the lifetime of the project $(\mathrm{kWh})$, based on the baseline electricity demand estimates developed earlier.

\subsection{Pico-hydro system sizing}

Pico-hydro systems are sized in the same manner as micro-hydro systems (see the previous section for more details on the sizing methodology).

\subsection{Pico-hydro capital costs}

The capital costs of a pico-hydro system is based on a $1 \mathrm{~kW}$ turbine with an electronic load controller, draft tube and draft channel. The low cost estimates are based on generic equipment (e.g. brandless Chinese 
Table 7: Pico-hydro capital cost estimates based on a $1 \mathrm{~kW}$ turbine of various builds.

\begin{tabular}{|l|c|c|c|}
\hline Equipment Item & $\begin{array}{c}\text { Probable } \\
\text { (USD/kW) }\end{array}$ & $\begin{array}{c}\text { Low } \\
\text { (USD/kW) }\end{array}$ & $\begin{array}{c}\text { High } \\
\text { (USD/kW) }\end{array}$ \\
\hline Pico-hydro turbine & 400 & 150 & 750 \\
\hline Draft tube and channel & 200 & 0 & 300 \\
\hline Electronic load controller & 150 & 50 & 200 \\
\hline TOTAL & 750 & 200 & 1250 \\
\hline
\end{tabular}

Table 8: $\quad$ Low voltage cable cost estimates.

\begin{tabular}{|l|l|l|l|}
\hline Equipment Item & $\begin{array}{l}\text { Probable } \\
\text { (USD/hh) }\end{array}$ & $\begin{array}{l}\text { Low } \\
\text { (USD/hh) }\end{array}$ & $\begin{array}{l}\text { High } \\
\text { (USD/hh) }\end{array}$ \\
\hline LV distribution cables & 120 & 70 & 150 \\
\hline Household wiring & 80 & 30 & 150 \\
\hline TOTAL & 200 & 100 & 300 \\
\hline
\end{tabular}

or Vietnamese made turbines), while the high cost estimates are based on quotes from Hydrotec Vietnam received in March 2010.

No labour costs have been allowed for since it is assumed that the pico-hydro system is selfconstructed by the village.

In addition to the cost of the pico-hydro turbine system, the costs for low voltage cables from the installation site to the end-users and household wiring (per household) are estimated as shown in table 8.

\subsection{Pico-hydro operations and maintenance costs}

O\&M costs associated with pico-hydro systems include turbine bearing and winding replacements, oiling of the bearings and basic electrical maintenance associated with the distribution equipment.

For the base financial model, it is assumed that the annual O\&M costs for pico-hydro are $10 \%$ of the capital costs. Over the lifetime of the project, the NPV of the O\&M costs is calculated as follows:

$$
O \& M_{N P V}=\frac{0.10 \times C A P E X}{r}\left[1-(1+r)^{-n}\right]
$$

\subsection{Pico-hydro replacement costs}

It is assumed that $75 \%$ of the capital cost needs to be replaced every 5 years, and this cost is spread over the period, i.e. the annual replacement cost is 15\% of the capital cost. Over the lifetime of the project, the NPV of the replacement costs is calculated as follows:

$$
R_{N P V}=\frac{0.15 \times C A P E X}{r}\left[1-(1+r)^{-n}\right]
$$

\subsection{Total cost of pico-hydro}

Putting the CAPEX, O\&M and replacement costs together, the total cost of pico-hydro (CAPEX + O\&M $+\mathrm{R})$ can be expressed as a linear equation of the form:

Cost $_{\text {pico }}=b_{1} H$

Where $H$ is the number of households in the village $b_{1}$ is the cost coefficient of the pico-hydro system (USD).

\section{COSTS OF SOLAR PHOTOVOLTAIC SYSTEMS}

The Levelised Cost of Electricity (LCOE) for solar PV systems is estimated by the following formula:

$$
L C O E=\frac{C A P E X+O \& M+R}{E}
$$

where LCOE is the levelised cost of electricity (USD/kWh)

CAPEX is the capital cost (installed) of the solar PV system (USD)

$O \mathcal{E} M$ is the operations and maintenance cost over the lifetime of the project, expressed as an NPV (USD)

$R$ is the replacement cost, expressed as an NPV (USD)

$E$ is the useful energy output of the grid extension over the lifetime of the project $(\mathrm{kWh})$, based on the baseline electricity demand estimates developed earlier. 


\subsection{Solar PV system sizing}

Based on the approximate load profile developed earlier and modelling in HOMER software, a system capable of producing $1 \mathrm{kWh}$ per day in the Lao PDR has the following components:

- 3 x 120 W solar PV array

- 12 V 630 Ah battery

- Solar charge controller.

To simplify the calculations, it is assumed that this system above can be scaled linearly to supply arbitrary electricity demands. For example, to supply $7 \mathrm{kWh}$ per day, 7 of the $1 \mathrm{kWh}$ systems above are required.

\subsection{Solar PV capital costs}

The capital costs for a $1 \mathrm{kWh} /$ day system described above are estimated based on standard trade prices for solar PV hardware (as at November 2011) as shown in table 9.

In addition to the solar PV generation equipment, the cost for low voltage distribution equipment (per household) is estimated as shown in table 10.

\subsection{Solar PV operations and maintenance costs}

O\&M costs associated with solar PV systems include cleaning the PV arrays, refilling the batteries with distilled water and regularly performing a battery equalisation charge.

For the base financial model, it is assumed that the annual O\&M costs for solar PV are $2 \%$ of the capital costs. Over the lifetime of the project, the NPV of the O\&M costs is calculated as follows:

$$
O \& M_{N P V}=\frac{0.02 \times C A P E X}{r}\left[1-(1+r)^{-n}\right]
$$

\subsection{Solar PV replacement costs}

The solar PV arrays and controllers are typically designed to last for the project lifetime of 20 years. Batteries can last between 4 to 10 years and will need to be replaced periodically.

It is assumed that $50 \%$ of the capital cost needs to be replaced every 10 years, and this cost is spread over the period, i.e. the annual replacement cost is $5 \%$ of the capital cost. Over the lifetime of the project, the NPV of the replacement costs is calculated as follows:

$$
O \& M_{N P V}=\frac{0.02 \times C A P E X}{r}\left[1-(1+r)^{-n}\right]
$$

\subsection{Total cost of solar PV}

Putting the CAPEX, O\&M and replacement costs together, the total cost of solar PV (CAPEX + O\&M + $\mathrm{R})$ can be expressed as a linear equation of the form:

Cost $_{\text {solar }}=b_{1} H$

where $H$ is the number of households in the village $b_{1}$ is the cost coefficient of the pico-hydro system (USD).

\section{BREAKEVEN DISTANCE ANALYSIS}

The breakeven distance is the distance (in $\mathrm{km}$ ) away from a village at which the cost of grid extension equals the cost of a DRE system (i.e. there would be different breakeven distances for micro-hydro, picohydro and solar PV).

Using the financial model articulated in this report, the breakeven distance can be calculated as a simple linear equation in terms of the number of households

Table 9: Solar PV capital cost estimates.

\begin{tabular}{|l|c|c|c|}
\hline Equipment Item & $\begin{array}{c}\text { Probable } \\
\text { (USD/System) }\end{array}$ & $\begin{array}{c}\text { Low } \\
\text { (USD/System) }\end{array}$ & $\begin{array}{c}\text { High } \\
\text { (USD/System) }\end{array}$ \\
\hline 3 x 120 W solar PV array & 1,050 & 900 & 1,500 \\
\hline 12 V 630 Ah battery & 1,800 & 1,350 & 2,340 \\
\hline Solar charge controller & 50 & 30 & 90 \\
\hline TOTAL & 2,900 & 2,280 & 3,930 \\
\hline
\end{tabular}

Table 10: Low voltage distribution cost estimates.

\begin{tabular}{|l|c|c|c|}
\hline Equipment Item & $\begin{array}{c}\text { Probable } \\
\text { (USD/hh) }\end{array}$ & $\begin{array}{c}\text { Low } \\
\text { (USD/hh) }\end{array}$ & $\begin{array}{c}\text { High } \\
\text { (USD/hh) }\end{array}$ \\
\hline 1500 W Inverter & 150 & 60 & 250 \\
\hline Household wiring & 80 & 30 & 150 \\
\hline TOTAL & 230 & 90 & 400 \\
\hline
\end{tabular}


in a village. In this section, the expression for the breakeven distance is derived, and then the results of the breakeven analysis are presented.

\subsection{Derivation of breakeven distance}

The cost models developed for grid extension and DRE technologies (micro-hydro, pico-hydro and solar PV) are linear and can be expressed as follows:

For Grid Extension:

$L C O E_{\text {grid }}=L R M C+\frac{a_{1} L+a_{2} H}{E}$

For DRE technologies:

$L C O E_{D R E}=\frac{b_{1} H}{E}$

where $L$ is the distance of grid extension $(\mathrm{km})$

$H$ is the number of households in the village

$E$ is the forecast household electricity demand at the end of the study period $(\mathrm{kWh})$

$a_{1}$ is the coefficient of the grid extension corresponding to the distance (USD)

$a_{2}$ is the coefficient of the grid extension corresponding to number of households (USD)

LRMC is the long run marginal cost of generation capacity (USD)

$b_{1}$ is the coefficient of the distributed renewable energy source (USD).

From the equations above, the breakeven distance between grid extension and a DRE system can be solved analytically as follows:

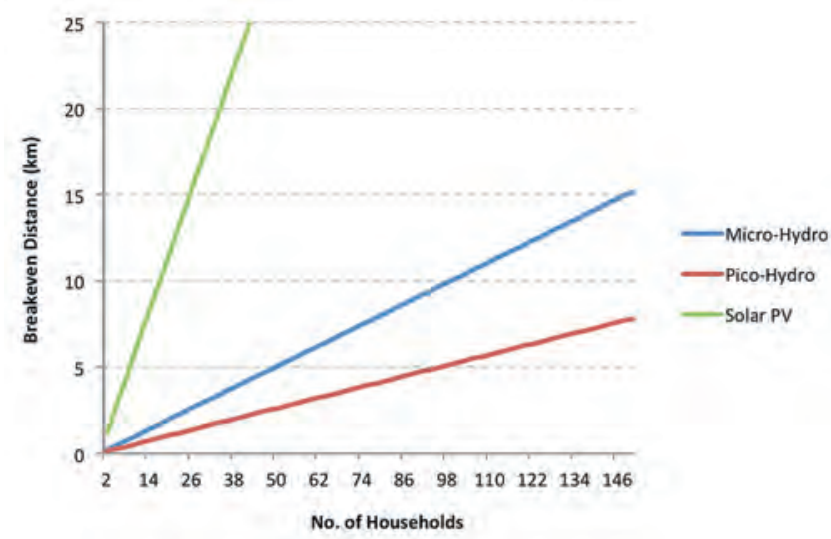

Figure 3: Comparison of the three DRE technologies compared with a $12.7 \mathrm{kV}$ SWER line grid extension for a village in the northern provinces.
$L_{\text {breakeven }}=\frac{\left(b_{1}-a_{2}-L R M C \times E\right)}{a_{1}} H$

At this distance, the total cost of grid extension is equal to the total cost of the DRE system. Therefore, the following two inferences can be made, if:

- Distance of grid extension $>$ breakeven distance, then the DRE system is the cheaper option

- Distance of grid extension < breakeven distance, then the grid extension is the cheaper option

\subsection{Analysis of breakeven distances}

Using the base parameters developed earlier in this paper, the breakeven distances for the DRE technologies (compared with grid extension) are computed for a range of household sizes. A project timescale of 20 years and a discount rate of $8 \%$ were used for the calculations.

Figure 3 shows a comparison of the three DRE technologies compared with a $12.7 \mathrm{kV}$ SWER line grid extension for a village with 0 to 150 households in the northern province. The breakeven distances on the graph are calculated for the electricity demand expected in the northern provinces and the most probable cost estimate (which is neither optimistic or pessimistic).

Similarly, the breakeven distances for a village in the southern provinces is shown in figure 4 .

As a general rule for comparison, a breakeven distance of $20 \mathrm{~km}$ is the threshold for the majority of grid extensions, i.e. with the exception of several of the more remote districts, most of the presently unelectrified villages are within $20 \mathrm{~km}$ of a grid supply.

It is evident that solar PV is not cost-competitive against grid extension (except for tiny villages of $<$ 15 households in the south and $<30$ households in the north). Even taking into account more optimistic electricity demand and capital cost scenarios, solar PV is still not an attractive alternative to grid extension. However, it must be remembered that these are judgements based on like-for-like comparisons and lower capacity solar PV systems (like solar home systems) could represent a more attractive option. After all, one would likely opt for a lower capacity system given the choice between it and no electricity at all.

Pico-hydro is the most compelling option from a cost perspective, showing low breakeven distances $(<20 \mathrm{~km})$ for the entire range of village sizes. The disadvantages of pico-hydro are more or less technical, particularly the availability of water resources and pico-hydro sites suitable to supply entire villages. Given a suitable water resource however, pico-hydro should be considered as a very cost-effective option in lieu of grid extension. 


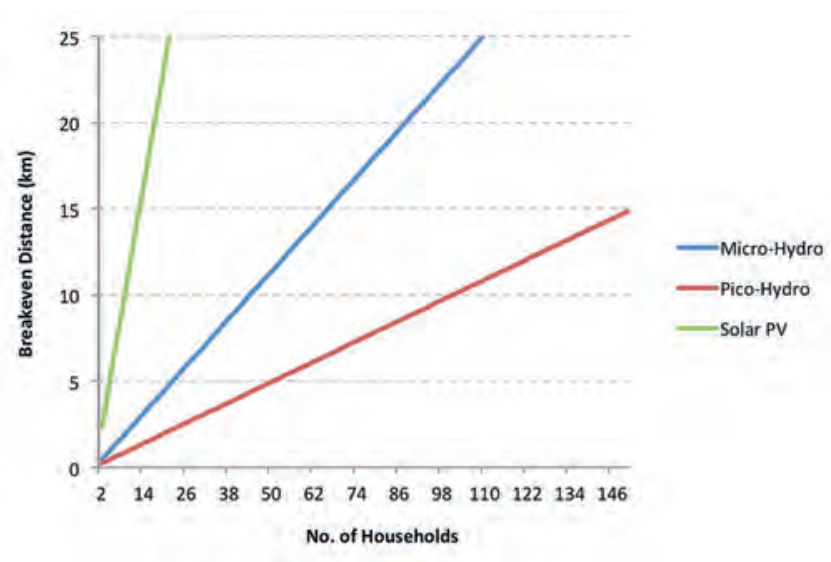

Figure 4: Breakeven distances for a village in the southern provinces.

Micro-hydro also presents itself as a reasonable alternative to grid extension, especially for smaller villages of $<60$ households. Provided that the right topography and water resource exists for a village scale system, micro-hydro can be cost-competitive against grid extensions and can typically be sized for a relatively high capacity.

The model was also run for a special demand scenario - very remote villages that are expected to use only minimal amounts of electricity (assumed to be $13 \mathrm{kWh} /$ month per household). The breakeven distances for these remote villages are shown in figure 5 .

Under these assumptions, all of the DRE technologies are cost-effective compared to grid extension.

\subsection{Mapping breakeven distances}

The use of GIS maps can provide a visual representation of breakeven distances. The following three maps show the breakeven distances for villages in Xiangkhuang province (in the centre-north of the Lao PDR) for the three DRE technologies - microhydro, pico-hydro and solar PV.

On the maps, the red dots and pink lines represent electrified villages and existing transmission lines respectively. The yellow crosses represent unelectrified villages and the yellow circles around them indicate the breakeven distances of the DRE technology against grid extension. Inside the yellow circle, grid extension is cheaper and outside the circle, the DRE technology is cheaper. Therefore, if a red dot (electrified village) or pink line (existing transmission line) falls within a yellow circle, then grid extension is the cheaper option for the village at the centre of the circle (yellow cross).

\section{LIMITATIONS OF THE MODEL}

The financial model proposed in this paper was conceived to compare grid extension and DRE technologies purely from a cost perspective. Therefore, there are aspects of the model that are not particularly

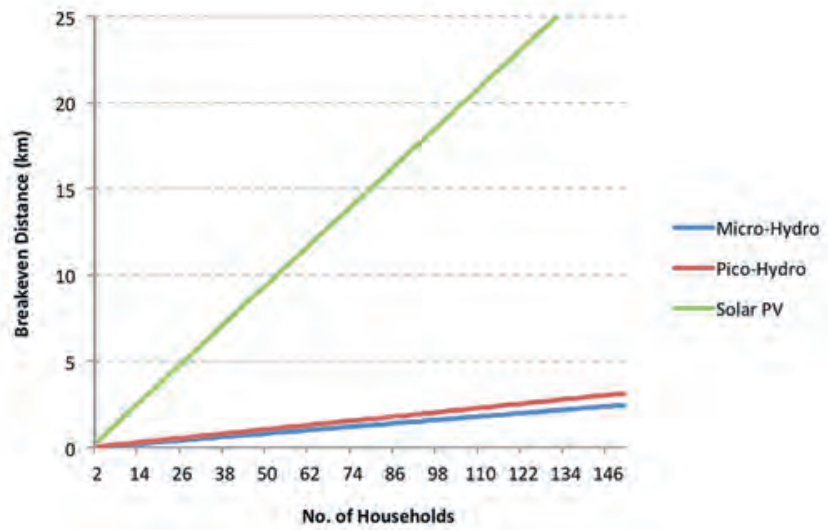

Figure 5: Breakeven distances for remote villages.

realistic. The following inherent limitations need to be borne in mind when interpreting the outputs of the model.

Firstly, the model takes a simplified approach to system sizing that does not consider the technical limits of the DRE technologies. For example, it would be inconceivable to see a 60 household village with $65 \mathrm{~kW}$ of pico-hydro turbines installed, but that is precisely what the model would imply for the average electricity demand scenario. Furthermore, it is almost impossible to know a priori (without a pre-feasibility survey) if a village has the natural resources available for a particular DRE technology. The model simply assumes that they do.

Secondly, the costs of grid extension in the model is independent of electricity demand. This is a simplifying assumption, but a reasonable one given that network planners would typically size the grid extension for a far higher rating than would be consumed by end-users.

Thirdly, the costing models for the DRE technologies (micro-hydro, pico-hydro and solar PV) are all linear. That is, the price per $\mathrm{kW}$ (or $\mathrm{kWh}$ ) is constant for all system sizes. In reality, one would probably expect a diminishing price per $\mathrm{kW}$ (or $\mathrm{kWh}$ ) as the size of the system increases, i.e. exploiting economies of scale.

Furthermore, the linear costing model implicitly assumes that systems can be purchased for an exact power demand. For example, if a village has a power demand of $52 \mathrm{~kW}$, the model assumes that a $52 \mathrm{~kW}$ DRE system can be purchased. However in reality, this is not always the case, particularly for systems with fixed unit sizes. In future, non-linear cost curves could potentially be added to account for these limitations.

Fourth, the annual growth rates in electricity demand are assumed to be static across the range of villages (i.e. $5 \%$ per year to 2020 and $4 \%$ thereafter). However, there is an asymmetrical link between the demand for electricity (and energy in general) and economic activity. 


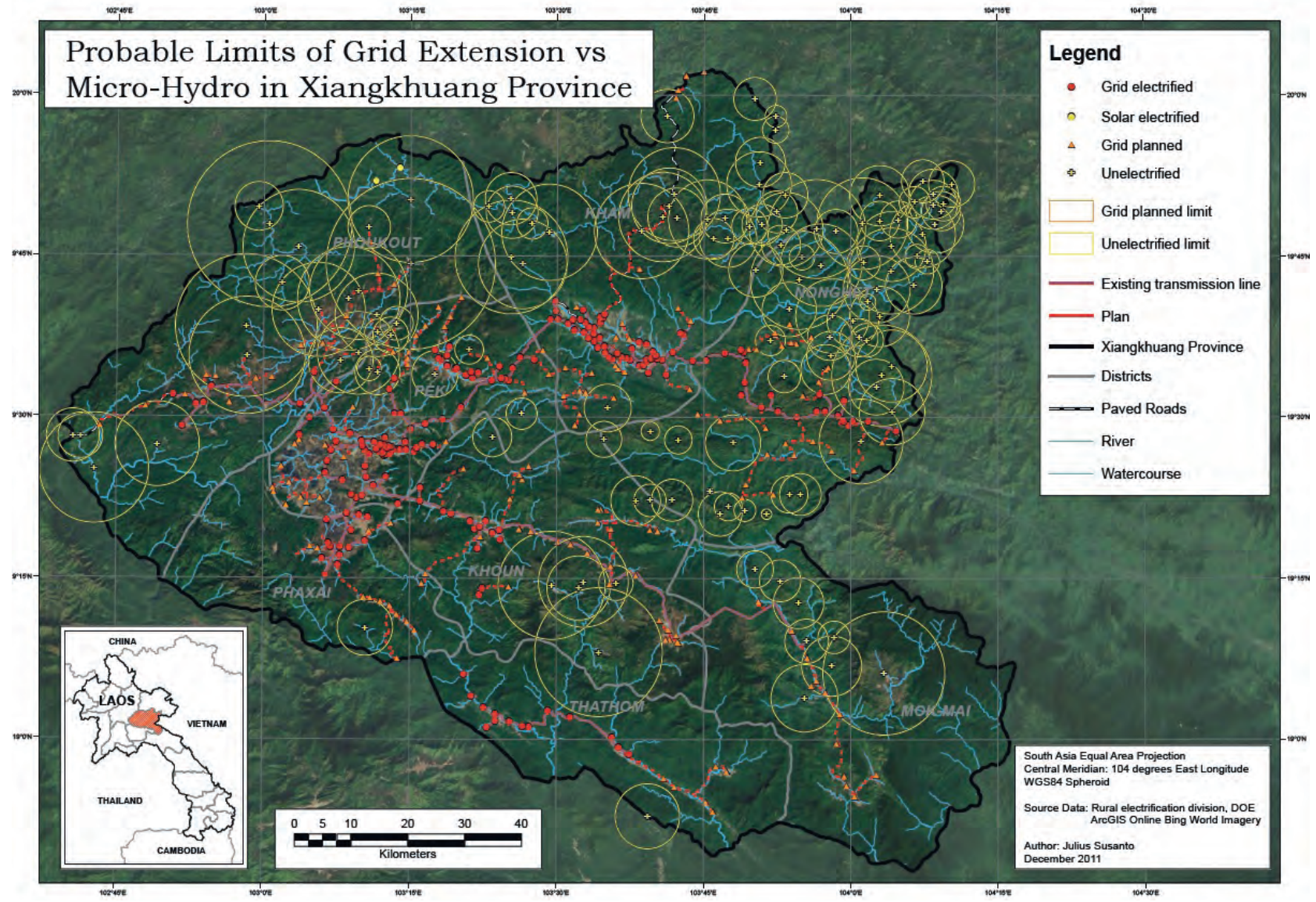

Figure 6: GIS visual representation - micro-hydro.

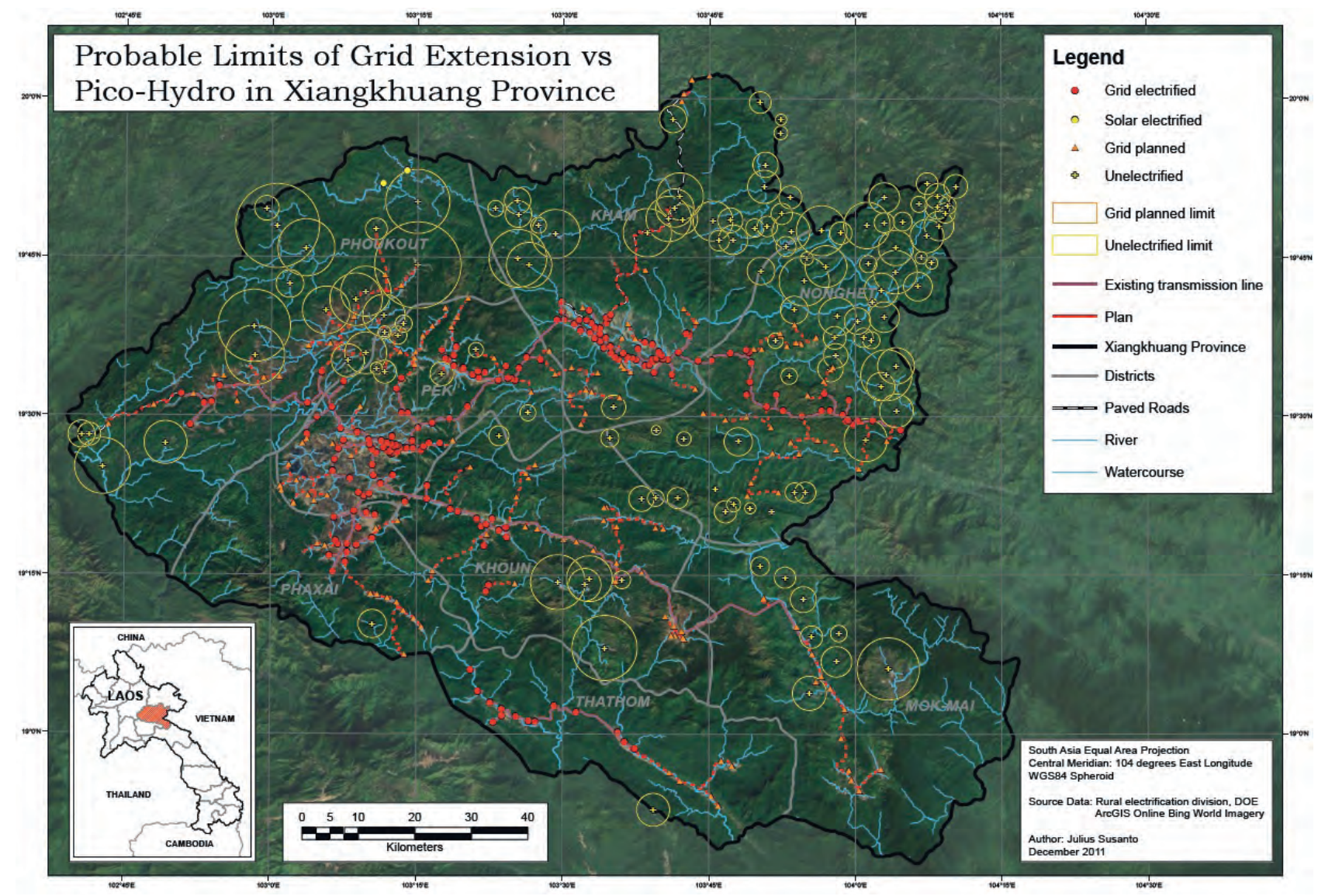

Figure 7: GIS visual representation - pico-hydro. 


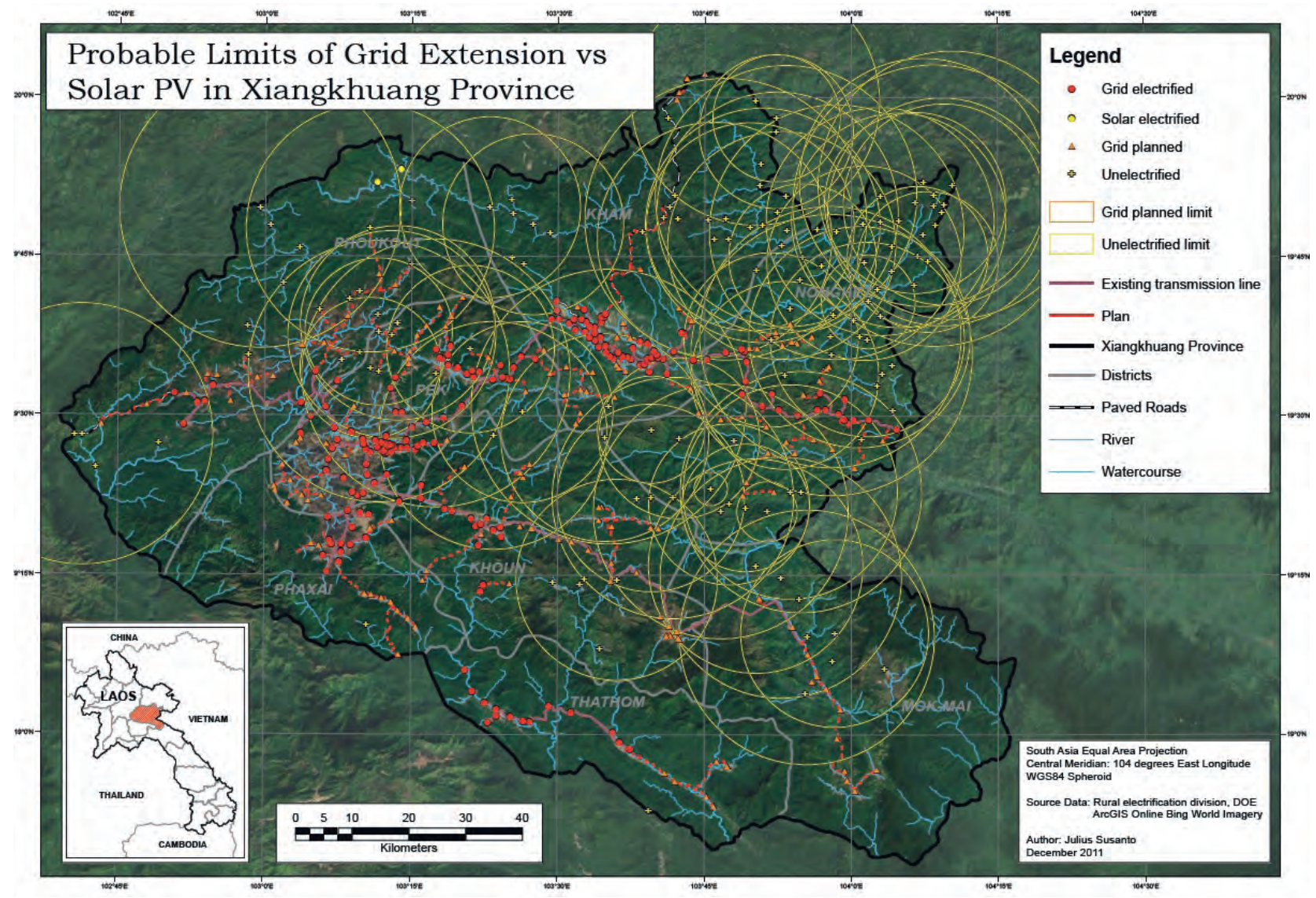

Figure 8: $\quad$ GIS visual representation - solar PV.

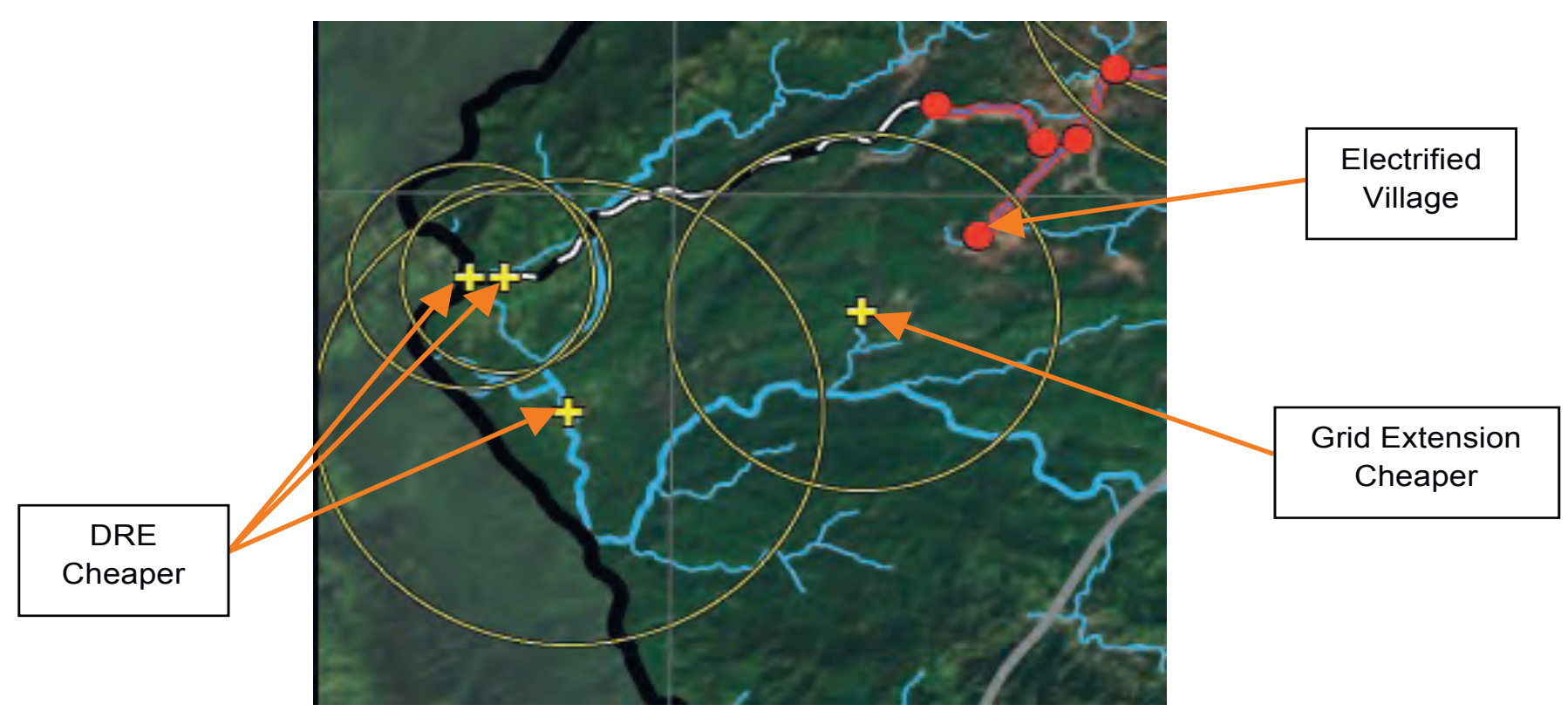

Figure 9: GIS visual representation enlargement. 
Access to electricity may not necessarily stimulate economic activity, but economic growth will almost certainly increase electricity demand. The model does not take into account the economic development prospects of the villages and the implications that growth (or lack thereof) will have on future electricity demand.

Lastly, the model has nothing to say about the quality of electricity supplied to the end-users. This applies to both grid extension and DRE technologies - both are subject to power supply interruptions and power quality problems (e.g. poor steady-state voltage regulation).

\section{CONCLUSIONS}

In this paper, a financial model was developed to compare grid extension versus three decentralised renewable energy options (micro-hydro, pico-hydro and solar PV). The results show that given available natural resources, micro-hydro and pico-hydro are viable alternatives to grid extension. Solar PV, however, is too costly on a like-for-like basis and any comparison with grid extension can only be made at reduced power outputs.

While the proposed model has limitations, it could potentially be used for screening purposes; to assist in the selection of villages to be electrified with DRE technologies instead of by grid extension. By calculating the breakeven distance of a DRE technology vs grid extension, one can use decision thresholds to determine whether a village could be a candidate for grid extension or a DRE technology.

However given the limitations described above, the model should be used as a complementary tool, in conjunction with natural resource assessments and village surveys.

\section{ACKNOWLEDGEMENTS}

This paper was adapted from a study commissioned by RISE, a project of Swiss NGO HELVETAS Laos. I'd like to thank Samuel Martin for his invaluable support and guidance, as well as Mattijs Smits and Chris Greacen, who both reviewed the drafts and provided very helpful comments.

\section{REFERENCES}

Cross, N., and Gaunt, C. T., 2003, Application of Rural Residential Hourly Load Curves in Energy Modelling, IEEE Bologna Power Tech Conference.

Dhungel, P., 2009, Financial and Economic Analysis of Micro-Hydro Power in Nepal, MSc Thesis, University of Minnesota.

Electricite du Laos, 2010, Power Development Plan 2010-2020, Lao PDR.

Electricite du Laos, 2011, Electricity Statistical Yearbook 2010, Lao PDR.

Fall, N., et al, 2007, Remote Area Power Supply (RAPS) Load and Resource Profiles, Sandia National Laboratories, Report SAND2007-4628.

Goldsmith, K., 1993, Economic and Financial Analysis of Hydropower Projects, Norwegian Institute of Technology.

Greacen, C., 2004, The Marginalization of "Small is Beautiful": Micro-hydroelectricity, Common Property, and the Politics of Rural Electricity Provision in Thailand, PhD thesis, University of California, Berkeley.

IEA, 2005, Projected Costs of Generating Electricity 2005 Update, OECD.

Ketjoy, N., 2005, Photovoltaic Hybrid Systems for Rural Electrification in the Mekong Countries, PhD dissertation, University of Kassel, Germany.

Lao Institute for Renewable Energy, 2011, Decentralised Production of Electricity in Lao PDR (on and off-grid) Scoping Phase Final Report, Lao PDR.

Nippon Koei / Lao Consulting Group, 2010, Rural Electrification Master Plan - Final Report - Volume 1: Task Part A, Lao PDR.

Vaidya, 2002, Cost and Revenue Structures for MicroHydro Projects in Nepal, AEPC.

World Bank, 2006, Technical and Economic Assessment of Off-Grid, Mini-Grid and Grid Electrification Technologies - Annexes, Washington DC. 